\title{
Reação de Genótipos de Mamoeiro à Varíola e à Podridão-do-pé
}

\author{
Alexei C. Dianese ${ }^{1 *}$, Luiz E.B. Blum ${ }^{1}$, Jaqueline B. Dutra ${ }^{1}$, Leonardo F. Lopes ${ }^{1}$, Mariana C. Sena ${ }^{2}$, \\ Leandro F. Freitas ${ }^{2} \&$ Osvaldo K. Yamanishi ${ }^{2}$
}

${ }^{1}$ Departamento de Fitopatologia; ${ }^{2}$ Faculdade de Agronomia e Veterinária, Universidade de Brasília, CEP 70910-900, Brasília, DF, Brasil, e-mail: luizblum@unb.br

Autor para correspondência: Luiz E. B. Blum

DIANESE, A.C., BLUM, L.E.B., DUTRA, J.B., LOPES, L.F., SENA, M.C., FREITAS, L.F. \& YAMANISHI, O.K. Reação

de genótipos de mamoeiro à varíola e à podridão-do-pé. Fitopatologia Brasileira 32:419-423. 2007.

\section{RESUMO}

Genótipos de mamoeiro (Carica papaya) ('NT Red', 'Golden', 'Baixinho de St. Amália', 'Sunrise Solo', 'Cross Paris', 'Tailândia Verde', 'Tailândia Roxo', 'Tailândia Roxão', 'Sekati' e 'Tainung-1') foram avaliados quanto à reação à varíola (Asperisporium caricae) e à podridão-do-pé (Phytophthora palmivora). O estudo foi conduzido em uma área com plantas naturalmente infectadas com ambos os patógenos e sob telado utilizando solo naturalmente infestado com $P$. palmivora. A severidade de varíola foi avaliada usando-se uma escala, de 1 ( $0-3 \%$ da superfície coberta por lesões) a 6 ( $>$ de $50 \%$ da superfície coberta por lesões). As avaliações foram feitas entre março e abril / 2003 e entre outubro 2003 e fevereiro 2004. A podridão-do-pé foi avaliada, no campo, por incidência em cada cultivar nos mesmos períodos. Nos experimentos sob telado a severidade da doença por $P$. palmivora foi avaliada em cada planta utilizando-se a seguinte escala: 0- sem sintomas; 1 - até 50\% de murcha; 2- de 51 a 100\% de murcha; 3- morta. Quanto à varíola, verificou-se que plantas de 'Sekati' (grupo Formosa) apresentaram os menores valores médios finais de severidade da doença na folhagem $(2,0)$ enquanto que, 'Golden' $(3,1)$ e'NT Red' $(3,7)$ apresentaram os maiores. Nos frutos, 'Tailândia Roxão' $(1,6)$, 'Tailândia Verde' $(1,7)$ e 'Sekati' (1,7) apresentaram os menores valores de varíola, enquanto que, 'Tailândia Roxo' $(2,3)$, 'Cross Paris' $(2,5)$, e 'Sunrise Solo' $(3,1)$ apresentaram os maiores. Quanto à podridão do pé, 'Tailândia Roxão' (grupo Formosa) apresentou a menor quantidade de doença, enquanto que, 'Golden', 'Sunrise Solo e 'NT Red' apresentaram os maiores valores.

Palavras-chave adicionais: Asperisporium caricae, Phytophthora palmivora, Carica papaya.

\begin{abstract}
Reaction of papaya genotypes to black-spot and foot-rot

Papaya (Caryca papaya) genotypes ('NT Red', 'Golden', 'Baixinho de St. Amália', 'Sunrise Solo', 'Cross Paris', 'Tailândia Verde', 'Tailândia Roxo', 'Tailândia Roxão', 'Sekati' and 'Tainung-1') were evaluated for resistance to blackspot (Asperisporium caricae) and foot-rot (Phytophthora palmivora). The study was conducted in an area where both pathogens occurred naturally and in a greenhouse using soil naturally infested with $P$. palmivora. Black-spot severity was evaluated using a scale, from $1(0-3 \%$ of the surface covered by lesions) to 6 ( $>$ of $50 \%$ of the surface covered by lesions). The evaluations were made between March / 2003 and April / 2003 and between October / 2003 and February / 2004. Foot-rot was evaluated, on the field trial, by counting the total number of plants with yellowing or wilt symptoms in the same period. On the greenhouse trials $P$. palmivora severity was evaluated in each plant using a scale from 0 (no wilt symptoms) to 3 (plant death). In relation to black-spot, the genotype 'Sekati' of the Formosa group presented the lowest average value of severity $(2,0)$ on the foliage while 'Golden' $(3,1)$ and NT Red' $(3,7)$ had the largest. 'Tailândia Roxão' $(1,6)$, 'Tailândia Verde' $(1,7)$ and 'Sekati' $(1,7)$ also had the lowest averages of severity on the fruit, while, 'Tailândia Roxo' $(2,3)$, 'Cross Paris' $(2,5)$, and 'Sunrise Solo' $(3,1)$ presented the largest. In relation to foot rot, 'Tailândia Roxão' (Formosa group) presented low amount of disease and 'Golden', 'Sunrise Solo, and 'NT Red' presented higher values.
\end{abstract}

Additional keywords: Asperisporium caricae, Phytophthora palmivora, Caryca papaya.

O mamoeiro (Carica papaya L.) é uma das plantas tropicais de maior importância na produção nacional e mundial de fruteiras (Nakasone, 1994). O Brasil é o maior produtor mundial de mamão, com uma produção estimada de 1,6 milhões de tonelada em 2005, porém desta, somente cerca de $2 \%$ é exportada (SBRT, 2006).

Parte da Tese de Doutorado do primeiro autor, Universidade de Brasília, Brasília DF. 2006.

*Endereço Atual: Embrapa Cerrados, Cx. Postal 08223, CEP 73310-970, Planaltina DF, Brasil.
As principais regiões produtoras encontram-se na Bahia e Espírito Santo (SBRT, 2006). Regiões com clima quente favorecem o cultivo do mamoeiro (Silva, 2001).

A varíola [Asperisporium caricae (Speg.) Maubl.] ou pinta-preta é uma das doenças mais comuns e pode ser uma das mais danosas. A doença incide diretamente nos frutos, depreciando-os comercialmente, e nas folhas, afetando o vigor das plantas. Santos \& Barreto (2003) relataram perdas causadas pela varíola na comercialização do mamão no estado de São Paulo de até 30\%. A varíola, apesar de ocorrer com grande freqüência em mamão (Ueno et al., 2001), é uma doença pouco estudada. Só recentemente 
iniciaram-se estudos epidemiológicos mais específicos sobre estratégias de controle utilizando fungicidas e a reação de diferentes genótipos à infecção por este patógeno (Santos \& Barreto, 2003). A podridão das raízes e dos frutos do mamoeiro, causada por Phytophthora palmivora (E.J. Butler) E.J. Butler é considerada em algumas regiões produtoras uma de suas principais doenças. No Brasil perdas de frutos da ordem de $7-10 \%$ já foram relatadas (Liberato et al., 1993).

Em relação ao mamoeiro, a pesquisa visando à resistência a $P$. palmivora ainda é incipiente (Oliveira et al., 2004). Drew et al. (1998) relataram procedimentos que tornavam viáveis hibridizações entre $C$. papaya e outras espécies do mesmo gênero que possuíam resistência ao vírus Papaya Ringspot Potyvirus-tipo P (PRSV-P). Esses cruzamentos também podiam ser utilizados para transferir outras características das espécies selvagens, como, por exemplo, a resistência a P. palmivora. Os híbridos resultantes foram plantados e testados. Dantas \& Lima (2001) relataram vários genótipos provenientes do Banco Ativo de Germoplasma de mamão (Cruz das Almas, BA), com níveis diferentes de tolerância a $P$. palmivora, no entanto, não foi especificado qual o método de avaliação dos genótipos e se estes continuaram em avaliação.

Visando incrementar as informações sobre a reação de genótipos quanto à resistência à varíola e à podridão do pé, variedades dos grupos Solo e Formosa foram avaliadas em experimentos de campo e sob telado em Brasília, Distrito Federal. Vale ressaltar que este tipo de estudo é fundamental para o desenvolvimento de plantas com resistência e para o manejo integrado das doenças no campo.

Experimentos em vasos sob telado - Os vasos foram mantidos sob telado $\left(24+/-4^{\circ} \mathrm{C}\right)$ em um viveiro da Estação Experimental de Biologia (EEB) da Universidade de Brasília, DF. Sementes, cedidas pela AGRONOL (Barreiras, BA), de quatro genótipos do grupo Solo ['NT Red', 'Golden', 'Baixinho de St. Amália', 'Sunrise Solo') e seis do grupo Formosa ('Cross Paris', 'Tailândia Verde', 'Tailândia Roxo', 'Tailândia Roxão', 'Sekati', 'Tainung-1') foram semeadas em bandejas (72 células) contendo fibra de coco $+5 \mathrm{~g} \mathrm{~L}^{-1}$ de 14 - 14 - 14 NPK (Osmocote - Scotts Co.) e mantidas sob telado.

Após dois meses da semeadura, as mudas com aproximadamente $10 \mathrm{~cm}$, foram transplantadas para vasos de $2 \mathrm{~L}$ contendo $1,8 \mathrm{~kg}$ de solo naturalmente infestado por Phytophthora. palmivora. Uma porção de solo naturalmente infestado com P. palmivora, retirada de um viveiro da EEB, foi homogeneizado e distribuída em 160 vasos. Neste solo haviam sido plantados mamoeiros há seis meses com alta incidência da doença.

Seguiu-se um delineamento em blocos ao acaso com dez tratamentos e quatro repetições de cada variedade. Cada unidade experimental foi composta de uma planta por vaso. Este experimento foi realizado duas vezes. A severidade da infecção de P. palmivora foi avaliada em cada planta utilizando-se a seguinte escala: 0 - sem sintoma aparente; 1 - até $50 \%$ de murcha na planta; 2 - de 51 a $100 \%$ de murcha; 3 - planta morta.

No primeiro experimento o plantio das sementes foi realizado em 7/7/2003 e o transplante das mudas em 26/9/2003. As avaliações foram feitas no período de 2/10/2003 a 12/11/2003, totalizando 20 avaliações, com um intervalo de dois dias entre as avaliações. Já, no segundo experimento o plantio foi realizado em 14/9/2003 e o transplante das mudas em 28/11/2003. A podridão-do-pé foi mais severa e o experimento foi encerrado após cerca de três semanas. As avaliações se deram no período de 4/12/2003 a 19/12/2003, totalizando seis avaliações, também com intervalo de dois dias entre as avaliações.

Os dados dos dois experimentos em conjunto foram submetidos à análise de variância não paramétrica em postos (Teste de Friedman) com repetição de medidas e as médias dos tratamentos comparados através do teste de SNK $(\mathrm{P} \leq 5$ $\%)$. A análise estatística dos dados foi realizada utilizandose o programa SigmaStat 2.0 (Jandel Corporation, 1995).

Experimento de Campo - O estudo foi implantado e conduzido entre 3/2003 e 2/2004 em uma área $(\sim 0,3 \mathrm{ha})$ da Estação Experimental de Biologia da Universidade de Brasília. Esta área foi anteriormente $(2 / 2000$ a 6/2002) ocupada por um experimento de competição de variedades de mamoeiro. As variedades do grupo 'Solo' foram semeadas em tubetes $(300 \mathrm{~mL})$ e as do grupo 'Formosa' foram semeadas em bandejas ( 72 células) no dia 15/07/02 . O substrato utilizado foi composto de $55 \mathrm{~L}$ de Plantmax (casca de Pinus, vermiculita e turfa - Eucatex Agro), $20 \mathrm{~L}$ de húmus e $365 \mathrm{~g}$ de 14N-14P-4K (Osmocote - Scotts Co.). As sementeiras foram mantidas em um telado.

No preparo do solo, foi utilizado $1100 \mathrm{~kg} \mathrm{ha}^{-1} \mathrm{de}$ calcário dolomítico (92,2\% de PRNT) que foi incorporado ao solo com grade aradora a $25 \mathrm{~cm}$ de profundidade. Posteriormente, foram preparados sulcos espaçados a 2,5 m e com profundidade de $35 \mathrm{~cm}$. Foram estabelecidas 21 covas por sulco com espaçamento de 2,2 m entre si. Aos sulcos foram adicionados $5 \mathrm{~kg} \mathrm{~m}^{-1}$ de cama de aviário e em cada cova foram adicionados e misturados $400 \mathrm{~g}$ de Superfosfato Simples, $50 \mathrm{~g}$ de KCl, $15 \mathrm{~g}$ de FTE BR-12. Quinze dias após, foram adicionados às covas $200 \mathrm{~g}$ de calcário dolomítico e 5 $\mathrm{g}$ de bórax.

O plantio ocorreu em 20/9/2002, transplantando-se seis mudas por cova a $20 \mathrm{~cm}$ uma da outra em duas linhas de $60 \mathrm{~cm}$ espaçadas de $30 \mathrm{~cm}$. Entre duas e três semanas após o transplante, eliminaram-se as plantas menos vigorosas e manteve-se uma planta por cova. Na irrigação das covas foi usado fita 'Santeno' tipo I com microperfurações a cada $15 \mathrm{~cm}$ e pressão de $0,80 \mathrm{~kg} \mathrm{~cm}^{-2}$ (Santeno Sistemas de Irrigação). Os genótipos plantados foram: 'NT Red', 'Golden', 'Baixinho de St. Amália' e 'Sunrise Solo' (grupo Solo) e 'Cross Paris', 'Tailândia Verde', 'Tailândia Roxo', 'Sekati' e 'Tailândia Roxão' (grupo Formosa). O genótipo 
Tainung-1 não foi plantado devido à quantidade insuficiente de sementes e conseqüentemente de mudas para transplante em campo.

A severidade da varíola nas folhas e nos frutos foi avaliada em cada planta utilizando-se a seguinte escala (Kranz, 1988): $1=0$ a 3\% da superfície de frutos ou folhas coberta por lesões; $2=$ de 4 a $6 \%$ da superfície de frutos ou folhas coberta por lesões; $3=$ de 7 a $14 \%$ da superfície de frutos ou folhas coberta por lesões; $4=$ de 15 a $24 \%$ da superfície de frutos ou folhas coberta por lesões; $5=$ de 25 a $50 \%$ da superfície de frutos ou folhas coberta por lesões; $6=$ acima de $50 \%$ da superfície de frutos ou folhas coberta por lesões.

A quantificação da doença causada por P. palmivora foi avaliada em cada genótipo e em cada período de avaliação, através da contagem do número de plantas com sintomas (murcha e amarelecimento foliar) na parcela experimental. Foram feitas avaliações, em intervalos semanais, em duas épocas do ano distintas: entre março e abril 2003 (início do período de estiagem, mas com neblina no período da madrugada) e entre outubro 2003 e fevereiro 2004 (período chuvoso).

O delineamento experimental usado foi o de blocos ao acaso. Cada cultivar foi considerado um tratamento com quatro repetições, de dez plantas entre março e abril 2003 (Total de 40 plantas) e seis plantas entre outubro 2003 e fevereiro 2004 (Total de 24 plantas). Os dados de incidência de doença dos dois períodos de avaliação foram em conjunto submetidos à análise de variância não paramétrica em postos (Teste de Friedman) com repetição de medidas e as médias de cada cultivar foram comparadas através do teste de SNK [Student-Newman-Keuls, $(\mathrm{P} \leq 5 \%)$ ] (Glantz, 1992). A análise dos dados foi realizada utilizando-se o programa estatístico 'SigmaStat 2.0' (Jandel Corporation, 1995).

Reação de genótipos de mamoeiro à varíola - $O$ genótipo 'Sekati' (grupo Formosa), apresentou o menor valor médio de severidade da varíola na folhagem (Tabela 1). Já, os genótipos 'NT Red' e 'Golden' (grupo Solo), e 'Cross Paris' (grupo Formosa), apresentaram os valores mais altos (Tabela 1). 'Sunrise Solo' e 'Baixinho de Santa Amália' (grupo Solo), 'Tailândia Verde' e 'Tailândia Roxo' (grupo Formosa), formaram um grupo intermediário de reação à doença. Este resultado aproxima-se aos relatos de Santos \& Barreto (2003).

Nos frutos, os genótipos 'Sunrise Solo', 'Tailândia Roxo' e 'Cross Paris' apresentaram os maiores valores médios de severidade da doença em relação aos demais. Os resultados das avaliações demonstraram diferentes níveis de resistência entre folhagem e fruto no mesmo cultivar, como, por exemplo, 'Sunrise Solo' e 'Golden' (Tabela 1). Como o objetivo é a produção de frutos sadios, concluiu-se que ao avaliar um cultivar para resistência à varíola a doença na folhagem teve importância menor. Além disso, embora tenha havido uma correlação positiva $(r=0,68$, significativo a $1 \%$ de probabilidade de erro), a resistência foliar não
TABELA 1 - Reação de severidade em folhas e frutos de genótipos de mamoeiro à varíola (Asperisporium caricae) em campo

\begin{tabular}{llll}
\hline \hline \multirow{2}{*}{ Genótipo } & \multirow{2}{*}{ Grupo } & \multicolumn{2}{c}{ Severidade $^{1}$} \\
\cline { 3 - 4 } & & Folha (1 -6) & Fruto (1 -6) \\
\hline Sunrise Solo & Solo & $2,6(2,3) \mathrm{b}^{2}$ & $3,1(3,0) \mathrm{a}$ \\
Cross Paris & Formosa & $3,1(2,7) \mathrm{a}$ & $2,5(2,8) \mathrm{a}$ \\
Tailândia Roxo & Formosa & $2,4(2,4) \mathrm{b}$ & $2,3(2,5) \mathrm{a}$ \\
Golden & Solo & $3,1(3,1) \mathrm{a}$ & $2,1(1,9) \mathrm{b}$ \\
NT Red & Solo & $3,7(3,5) \mathrm{a}$ & $2,0(1,9) \mathrm{b}$ \\
Baixinho de Santa & Solo & $2,5(2,5) \mathrm{b}$ & $1,8(1,6) \mathrm{b}$ \\
Amália & & & \\
Tailândia Verde & Formosa & $2,4(2,2) \mathrm{b}$ & $1,7(1,8) \mathrm{b}$ \\
Sekati & Formosa & $2,0(1,6) \mathrm{c}$ & $1,7(1,9) \mathrm{b}$ \\
Tailândia Roxão & Formosa & $2,2(2,2) \mathrm{b}$ & $1,6(1,4) \mathrm{b}$ \\
\hline
\end{tabular}

${ }^{1} 1=0-3 \%$ da superfície de frutos ou folhas coberta por lesões; $2=$ de 4 a $6 \%$ da superfície de frutos/folhas coberta por lesões; $3=$ de 7 a 14 $\%$ da superfície de frutos/folhas coberta por lesões; $4=$ de 15 a $24 \%$ da superfície de frutos/folhas coberta por lesões; $5=$ de 25 a $50 \%$ da superfície de frutos/folhas coberta por lesões; $6=$ acima de $50 \%$ da superfície de frutos/folhas coberta por lesões.

${ }^{2}$ Média e mediana (entre parênteses) de dois experimentos de campo com repetições de medidas ao longo do tempo. ${ }^{3}$ Médias e medianas (entre parênteses) seguidas por letras iguais não diferem significativamente pelo Teste de SNK (5\%), conduzido após a confirmação da significância dos dados através do teste não paramétrico de Friedman (Análise de Variância Não Paramétrica em Postos com Repetição de Medidas).

necessariamente garante resistência nos frutos.

Existem diversos mecanismos de resistência a patógenos, os quais incidem sobre folhas e frutos, que podem ser inerentes aos cultivares, os quais retardam o desenvolvimento da varíola. Características morfológicas de frutos como baixo número de lenticelas, a espessura e o número de camadas da epiderme e hipoderme, além dos compostos que constituem a cutícula e a cera que os revestem externamente já foram positivamente correlacionados com a resistênciaadiversos patógenos(Gabler etal.,2003).Aindaem relação à infecção foliar, características morfológicas como estômatos pequenos e pouco numerosos, um parênquima paliçádico compacto, epiderme e cutícula espessas e a presença de tricomas na superfície abaxial também foram correlacionados positivamente com a resistência (Mayee \& Suryawanshi, 1995). Outro fator que pode contribuir é a capacidade dos cultivares de responder à infecção através do reconhecimento da presença do patógeno e assim induzir, por exemplo, a produção de enzimas de defesa como a $\beta-1-3$ glucanase, a peroxidase e a quitinase (Dangl \& Jones, 2001; Zhu et al., 2003).

Reação de genótipos de mamoeiro à podridão-do-pé - No presente estudo de campo, 'Tailândia Roxão' (grupo Formosa) apresentou a menor quantidade de doença, a qual foi significativamente diferente dos valores apresentados pelos demais genótipos (Tabela 2). Em experimentos 
TABELA 2 - Reação de genótipos de mamoeiro à podridão-do-pé (Phytophthora palmivora) em telado e em campo

\begin{tabular}{|c|c|c|c|}
\hline \multirow[t]{2}{*}{ Genótipo } & \multirow[t]{2}{*}{ Grupo } & \multirow{2}{*}{$\begin{array}{c}\text { Telado } \\
\text { Severidade }(0-3)^{1}\end{array}$} & \multirow{2}{*}{$\begin{array}{c}\text { Campo } \\
\begin{array}{c}\text { Número de } \\
\text { plantas }^{2}\end{array}\end{array}$} \\
\hline & & & \\
\hline Tailândia Verde & Formosa & $2,3(2,8) \mathrm{a}^{3}$ & $6,0(6,0) b^{3}$ \\
\hline Sunrise Solo & Solo & $2,2(2,6) b$ & $12,8(12,9) b$ \\
\hline Tainung -1 & Formosa & $2,1(2,6) b$ & Não plantado 4 \\
\hline Sekati & Formosa & $2,1(2,6) b$ & $8,8(8,9) \mathrm{b}$ \\
\hline Golden & Solo & $2,0(2,4) b$ & $12,3(14,0) \mathrm{a}$ \\
\hline NT Red & Solo & $1,9($ & $12,8(14,0) \mathrm{a}$ \\
\hline $\begin{array}{l}\text { Baixinho de Santa } \\
\text { Amália }\end{array}$ & Solo & $1,9(2,1) b$ & $6,0(6,0) b$ \\
\hline Tailândia Roxo & Formosa & $1,8(2$ & $4,3(3,0) b$ \\
\hline Cross Paris & Formosa & 1,6 & $7,0(7,0) b$ \\
\hline Tailândia Roxão & Formosa & $1,0(0,8) \mathrm{d}$ & $3,3(3,0) b$ \\
\hline \multicolumn{4}{|c|}{$\begin{array}{l}{ }^{1} 0 \text { - sem sintoma aparente; } 1 \text { - até } 50 \% \text { de murcha na planta; } 2 \text { - de } 51 \text { a } \\
100 \% \text { de murcha; } 3 \text { - planta morta. }{ }^{2} \text { Número médio de plantas afetadas } \\
\text { (40 plantas no experimento de março a abril de } 2003 \text { ou } 24 \text { plantas } \\
\text { no experimento entre outubro de } 2003 \text { e fevereiro de } 2004 \text { ). }{ }^{3} \text { Média } \\
\text { e mediana (entre parênteses) de dois experimentos de campo com } \\
\text { repetições de medidas ao longo do tempo. Médias e medianas (entre } \\
\text { parênteses) seguidas por letras iguais não diferem significativamente } \\
\text { pelo Teste de SNK (5\%), conduzido após a confirmação da significância } \\
\text { dos dados através do teste não paramétrico de Friedman (Análise de } \\
\text { Variância Não Paramétrica em Postos com Repetição de Medidas). }{ }^{4} \text { ara } \\
\text { Tainung-1: Genótipo não plantado devido à quantidade insuficiente } \\
\text { de sementes e conseqüentemente de mudas para transplante. }\end{array}$} \\
\hline
\end{tabular}

realizados em telado, 'Tailândia Roxão' (grupo Formosa) apresentou a média mais baixa de severidade (Tabela 2).

Existem diversos mecanismos de resistência a Phytophthora e outros patógenos de solo que poderiam explicar a resistência observada em 'Tailândia Roxão'. Características morfológicas da raiz como lenhosidade e espessura da epiderme poderiam estar relacionadas à resistência à podridão do pé. Ambas são citadas por Cooper et al. (2004) ao descreverem a resistência do genótipo de cenoura 'Purple Turkey' à infecção por Pythium violae Chesters \& Hickman, causador da mancha seca. Outra característica seria a organização interna das células da raiz, que por serem menores, em relação às células das variedades comercias, acabaram aumentando a quantidade de barreiras físicas dificultando a dispersão do patógeno no tecido radicular (Cooper et al., 2004). A ocorrência de resistência de planta adulta à infecção por Phytophthora foi descrita por Jeun \& Hwang (1991) no patossistema pimentão (Capsicum annuum) - Phytophthora capsici Leonian e também pode estar ocorrendo com os cultivares de mamão, como já foi descrito acima. Segundo Jeun \& Hwang (1991), a resistência estaria relacionada com mudanças morfológicas e nutricionais durante o desenvolvimento das plantas hospedeiras. A produção de substâncias que retardam o desenvolvimento do patógeno após a penetração na raiz é outro fator que deve ser levado em conta. Widmer et al. (1998) descreveram a existência de fatores putativos de resistência nas raízes de porta-enxertos de laranjeira tolerantes à infecção por
P. palmivora. A ação de enzimas como a peroxidase, a polyfenol-oxidase e a fenilalanina amônia-liase, todas produzidas em resposta à infecção por $P$. palmivora em cacau (Okey et al., 1997), também deve ser levada em consideração. Zhu et al. (2003) induziram resistência em mamão contra $P$. palmivora através de aplicações de BTH (Benzothiadiazole), esta substância incitou um aumento na atividade de $\beta$-1-3 glucanase e quitinase.

Os resultados deste estudo confirmaram a susceptibilidade à varíola e à podridão-do-pé dos genótipos do grupo 'Solo' cultivados no Brasil. Este fato indica a necessidade de trabalhos de melhoramento genético que visem genótipos menos susceptíveis a estas e a outras doenças do mamoeiro. Conclui-se, portanto, que o genótipo 'Tailândia Roxão', embora carente de características agronômicas para a comercialização, foi o que mostrou menor susceptibilidade à varíola e à podridão-do-pé. Este genótipo, seria promissor nos programas de melhoramento visando a obtenção de cultivares comerciais menos susceptíveis a estas doenças.

\section{AGRADECIMENTOS}

O primeiro e o segundo autores agradecem, respectivamente, à Coordenação de Aperfeiçoamento de Pessoal de Nível Superior - CAPES e ao Conselho de Desenvolvimento Científico e Tecnológico - CNPq pela concessão de bolsa de estudo e de produtividade em pesquisa. Os autores agradecem ao Conselho Nacional de Desenvolvimento Científico e Tecnológico - CNPq e a empresa AGRONOL (Barreiras, BA) pelo fornecimento das sementes dos genótipos de mamoeiro.

\section{REFERÊNCIAS BIBLIOGRÁFICAS}

COOPER, C., ISAAC, S., JONES, M.G., CROWTHER, T., SMITH, B.M. \& COLLIN, H.A. Morphological and biochemical response of carrots to Pythium violae, causative agent of Cavity Spot. Physiological and Molecular Plant Pathology 64:27-35. 2004.

DANGL, J.L. \& JONES, J.D.G. Plant pathogens and integrated defense responses to infection. Nature 411:826-833. 2001.

DANTAS, J.L.L. \& LIMA, J.F. Selection and recommendation of papaya varieties: evaluation of lines and hybrids. Revista Brasileira de Fruticultura 23:617-621. 2001.

DREW, R.A., O'BRIAN, C.M. \& MAGDALITA, P.M. Development of Carica interspecific hybrids. Acta Horticulturae 461:285-291. 1998.

GABLER, F.M., SMILANICK, J.L., RAMMING, D.W. \& MACKEY, B.E. Correlations of morphological, anatomical, and chemical features of grape berries with resistance to Botrytis cinerea. Phytopathology 93:1263-1273. 2003.

GLANTZ, S.A. Primer of biostatistics. New York McGraw-Hill, Inc. $3^{\text {rd }}$ ed. 1992.

JEUN, Y.C. \& HWANG, B.K. Carbohydrate, amino acid, 
phenolic and mineral nutrient contents of pepper plants in relation to age-related resistance to Phytophthora capsici. Journal of Phytopathology 131:40-52. 1991.

KRANZ, J. Measuring plant disease. In: Kranz, J. \& Rotem, J. (Eds.) Experimental techniques in plant disease epidemiology. Berlin. Springer Verlag. 1988. pp. 35-50.

LIBERATO, J.R., VANETTI, C., RODRIGUES, C.H. \& DIAS V.P. Ocorrência de podridão de Phytophthora em mamoeiro (Carica papaya L.) no Estado do Espírito Santo. Fitopatologia Brasileira 18:324. 1993.

MAYEE, C.D. \& SURYAWANSHI, A.P. Structural defense mechanisms in groundnut to late leaf spot pathogen. Indian Phytopathology 48:160-165. 1995.

NAKASONE, H.Y. Papaya. In: Ploetz, R.C., Zentmyer, G.A., Nishijima, W.T., Rohrbach, K.G. \& Ohr, H.D (Eds.) Compendium of tropical fruit diseases. Saint Paul MN. APS Press. 1994. pp. 5657.

OKEY, E.N., DUNCAN, E.J., SIRJU-CHARRAN, G. \& SREENIVASAN, T.N. Phytophthora canker resistance in cacao: role of peroxidase, polyphenoloxidase and phenylalanine ammonialyase. Journal of Phytopathology 145:295-299. 1997.

OLIVEIRA, A.A.R., LEAL, L. C. \& DANTAS, J.L.L.
Performance of papaya (Carica papaya L.) genotypes in the severity of root rot. Third International Symposium on Tropical and Subtropical Fruits: Program and Abstracts. Fortaleza, CE, Brazil. 2004. p.84 (Abstract)

SANTOS, M.C. \& BARRETO, M. Estudo epidemiológico da varíola do mamoeiro em cultivares submetidos a tratamentos com fungicidas. Summa Phytopathologica 29:141-146. 2003.

SBRT. Serviço Brasileiro de Respostas Técnicas. Informações sobre exportação de frutas. Disponível em: <http:sbrt.ibict.br/ upload/sbrt2085.pdf>. Acesso em 14/6/2006.

SILVA, G.S. Podridão das raízes e dos frutos do mamoeiro. In: Luz, E.D.M.N., Santos, A.F., Matsuoka, K. \& Bezerra, J.L. (Eds.) Doenças causadas por Phytophthora no Brasil. Campinas SP. Livraria e Editora Rural. 2001. pp. 413-432.

WIDMER, T.L., GRAHAM, J.H. \& MITCHELL, D.J. Histological comparison of fibrous root infection of disease-tolerant and susceptible citrus hosts by Phytophthora nicotianae and $P$. palmivora. Phytopathology 88:389-395. 1998.

ZHU, Y.J., QIU, X., MOORE, P.H., BORTH, W., HU, J., FERREIRA, S. \& ALBERT, H.H. Systemic acquired resistance induced by BTH in papaya. Physiological and Molecular Plant Pathology 63:237-248. 2003.

Recebido 27 Dezembro 2006 - Aceito 16 outubro 2007 - FB 7001 